\title{
FENOMENOLOGIA E CRISE DA ARQUITETURA
}

\author{
José Luiz Furtado* \\ josefurtado1956@hotmail.com
}

\begin{abstract}
RESUMO Ao se fazer no espaço limítrofe entre a engenharia e a arte, a arquitetura enfrenta simultaneamente problemas estéticos e técnicos. Esta situação a torna tarefa sempre inacabada, ciência tecida no diálogo constante entre dois valores e fazeres tradicionalmente antagônicos. Diante desse quadro, busca-se comumente enraizar a arquitetura em fundamentos exteriores aos seus próprios conceitos, seja na improvisação criadora dos indivíduos, inerente à vida urbana, ou nos diversos saberes sobre o homem que equacionam as necessidades universais às quais ela deveria responder. Estas considerações preliminares conduzem ao cerne de uma questão propriamente filosófica acerca dos fundamentos pré-reflexivos do mundo da vida (Lebenswelt) $e$, no caso da arquitetura, sobre a experiência do habitar que constitui o campo ontológico "regional" de onde parte a ciência/arte aqui investigada.
\end{abstract}

Palavras-Chave Arquitetura; Fenomenologia; Estética

ABSTRACT Architecture faces technical and aesthetical problems since it exists in the space between Engineering and Art. This situation turns Architecture into an endless task, a science made in a ceaseless dialogue between two traditional antagonistic values. Art and Engeneering seek to base Architecture in foundations that are outside its own concepts, either when they try to base it in creative improvisation of individuals in their urban lives or

* Professor do Departamento de Filosofia da Universidade Federal de Ouro Preto. Artigo recebido em 15/09/05 e aprovado em 15/11/05.

KRITERION, Belo Horizonte, $\mathbf{n}^{\circ}$ 112, Dez/2005, p. 414-428 
when they try to put its roots in several different cognizances about humankind to which it should respond. This introductory essay intends to take us to the experience of inhabitation which constitutes the ontological "region" where this science/art departs from.

Keywords Architecture; Phenomenology; Aesthetics

\section{I - A crise da arquitetura}

A questão das relações entre fenomenologia e arquitetura situa-nos, primeiramente, diante de problemas mais gerais, característicos das relações entre a filosofia e as diversas ciências práticas. Sob qualquer perspectiva que se pense esta relação, salta aos olhos o caráter acima de tudo teórico da reflexão filosófica em oposição à ciência. Já na sua "lógica formal" Husserl distingue entre o interesse técnico que anima a prática das diversas ciências e o filosófico. ${ }^{1}$ O primeiro, visando a produção de efeitos no mundo, apóia-se na eficácia das teorias para definir o critério da verdade. Tal posição permite ao cientista e ao técnico operar com teorias cujos pressupostos e conceitos de base ainda não estão suficientemente esclarecidos quanto a seu sentido pleno e suas condições de validade, porque este tipo de aprofundamento esclarecedor não interfere, freqüentemente, no resultado da sua aplicação técnica. As matemáticas, por exemplo, funcionaram muito bem, mesmo sem uma definição satisfatória do próprio número ou do que fosse, propriamente falando, o estatuto das relações e das leis da lógica.

No entanto, nos momentos de crise da pesquisa científica, estes pressupostos e conceitos não esclarecidos guiam a investigação, conduzindo-a a retomar seu sentido autêntico, uma vez que atuam ao modo de horizonte, já direcionando o olhar do sábio antes que sua própria ciência se constituísse como tal. De fato, a distinção entre fenômenos físicos e biológicos é anterior à existência da física propriamente dita, dela partindo o cientista para levantar seus problemas. Do mesmo modo, para o caso que nos interessa aqui, o habitar é uma experiência fundamental do homem a anteceder toda ciência, no sentido exatamente idêntico ao que Merleau-Ponty dizia ser o mundo "mais velho do que todo pensamento", e a paisagem, anterior à geografia. É então a esta experiência fundamentalmente não conceitual da moradia, designadora de uma das formas originárias de estar no mundo, que a arquitetura deve retornar sempre

1 HUSSERL. Logique formale et logique transcendentale, p. 228. 
que experimentar uma crise em seus fundamentos, retomando o enraizamento sensível, sustentador do sentido autêntico do seu fazer, contra as construções especulativas de toda ordem.

O termo grego krísis define uma região de fronteira, uma situação limite, as conjunturas perigosas, e, por isso mesmo, decisivas. Outra não é a situação da arquitetura ao se fazer no espaço limítrofe entre a engenharia e a arte, enfrentando simultaneamente problemas estéticos e técnicos, as exigências de beleza e funcionalidade da obra. Esta precariedade é, ao mesmo tempo, fonte da riqueza que torna a arquitetura tarefa sempre inacabada, ciência tecida no diálogo constante com dois valores e fazeres tradicionalmente antagônicos, em uma distensão, portanto, que a alimenta de vida.

Mais do que isso, o fazer arquitetônico esposa, quiçá, a principal contradição da nossa época, a saber, a existente entre a fruição desinteressada e prazerosa da beleza e a racionalidade instrumental, serva do cálculo, da exatidão, da eficácia. Na história da arquitetura, esta contradição interiorizada irá opor, por exemplo, Corbusier e a corrente fenomenológica. O primeiro, a falar de necessidades humanas calculáveis; a segunda, a buscar na cidade, em seus monumentos, casas, edifícios, uma ordem orgânica e espontânea dos lugares inspirada pela potência criadora e irrefletida da vida. Porém, ambos buscam enraizar a arquitetura em fundamentos exteriores aos seus próprios conceitos, em uma espontaneidade criadora subjacente à vida urbana, ou nos diversos saberes sobre o homem que equacionam as necessidades universais às quais a arquitetura deveria responder.

Estas considerações preliminares conduzem-nos de volta ao cerne da questão. Dissemos que a reflexão fenomenológica incide sobre o fundamento pré-reflexivo da arquitetura, a saber, sobre a experiência do habitar, que constitui o campo ontológico particular ou "regional" de onde parte a ciência/arte aqui posta em questão. Afirmamos também que, nos momentos de crise, as ciências costumam retornar a seus fundamentos irrefletidos, a fim de esclarecerem seus respectivos ideais reguladores. A crise da arquitetura consiste nesta dupla conexão que a divide entre a estética e a técnica. $\mathrm{O}$ retorno à experiência fenomenológica e existencial do habitar permitirá precisar o sentido do fazer arquitetônico ao prescindir desta dicotomia e retornar ao momento vivido, no qual funcionalidade e fruição da beleza se apresentam unidas.

Sendo um modo de estar-em si primitivo e familiar, não carregado de conceituações filosóficas, o habitar permite compreender de outra forma as relações vividas entre a alma e o corpo, o pensamento e a linguagem, o sentido e a fala, o espaço e o tempo, entre tantas outras dicotomias conceituais irreconciliáveis presentes no pensamento do homem ao longo da tradição 
metafísica ocidental. A experiência de habitar — para a qual Merleau-Ponty tantas vezes chamava a atenção - define uma modalidade de relação em que dois termos se imbricam essencialmente um no outro, se entrelaçam formando um amálgama do qual só se distinguem por abstração. Assim, a impossibilidade de pensar o homem fora do seu enraizamento originário no espaço/tempo do mundo, baliza a reflexão fenomenológica sobre as relações entre sujeito e objeto.

\section{II - O habitar}

Como já afirmamos, habitar é algo cujo sentido todos nós sabemos de um modo não conceitual, ou, se queremos, prático, pois trata-se de uma dimensão fundamental da existência. A casa é seguramente o âmbito mais patente onde ocorre o fenômeno da circunvisão da categoria principal da pragmática de Ser e Tempo, de Heidegger. O mundo da vida cotidiana é o horizonte onde se desdobram as tarefas da existência e o conjunto das referências que se articulam entre as coisas a partir daquelas. Ser-no-mundo significa, nesse sentido, afirma Heidegger, "o empenho não temático, guiado pela circunvisão, nas referências constitutivas da manualidade de um conjunto instrumental". ${ }^{2}$ Assim, o âmbito da circunvisão, da ocupação, fixa a distância originária das coisas, determinando também a direção de acesso a elas, porque se encontra sempre já previamente orientada pelas tarefas atualmente realizadas por nós. Em função disso, os objetos recebem uma determinada orientação, ou melhor, certa disposição orientada. O livro de Heidegger está aberto à minha direita, porque sou destro e trabalho com ele agora. Mas a orientação efetiva, em sentido ontológico, que o utensílio recebe na existência diz respeito, principalmente, ao seu sentido de ser. Próximo é aquilo na direção de que a existência se distende, para o que ela se encontra "voltada" e direcionada. "Todos os onde", escreve Heidegger, "são descobertos e interpretados na circunvisão, através das passagens e caminhos do modo de lidar cotidiano, e não constatados e enumerados numa leitura e medições do espaço". ${ }^{3}$ O lugar é, originariamente, o sítio de onde uma coisa nos vem ao encontro, aberto pela preocupação. Antes de ser habitado, o espaço da moradia é já pré-ocupado. O olhar de quem a habita tem a forma pré-determinante de um ver-em-torno-em-busca-de orientado praticamente pela preocupação de realizar uma tarefa.

Era a este tipo de saber experimentado, vivido, que Santo Agostinho se referia, nas Confissões, afirmando saber o que era o tempo sem poder defini-lo

2 HEIDEGGER. El ser y el tiempo, § 16, p. 119.

3 HEIDEGGER. El ser y el tiempo, § 22, p. 151. 
ou conceituá-lo, caso lhe pedissem que o fizesse. Pois bem, sendo assim, podemos inicialmente prescindir da arquitetura, de todo conhecimento técnico, de toda engenharia adquirida e mesmo de toda experiência histórica não sedimentada imediatamente no dado visado pela consciência, quando interrogamos a experiência de habitar. Segundo Henry Lefebvre, esta experiência foi frequientemente substituída pela investigação acerca do lugar da habitação:

\footnotetext{
"O habitar, prática milenar expressada incorretamente, inadequadamente na linguagem e no conceito, mais ou menos viva ou decadente, mas que seguia sendo concreta (...) desapareceu do pensamento e deteriorou-se consideravelmente na prática no reinado do lugar da habitação" tendo sido necessária a "mediação filosófica de Nietzsche e Heidegger para tentar recuperar o sentido do habitar". ${ }^{4}$
}

Por esta via a arquitetura em crise deveria, retomando a experiência da moradia, rever seus conceitos. Para falar como Husserl, seria preciso por entre parênteses toda afirmação e todo juízo não originalmente fundamentados sobre a intuição da coisa visada, em carne e osso, no caso o próprio ato vivido de habitar. Evidentemente, a fenomenologia não poderia dar conta das infinitas práticas empíricas, sociais e históricas da habitação. O habitar sobre o qual nos debruçamos é, primeiramente, simples possibilidade eidética obtida por variação imaginária a partir da experiência fenomenologicamente compreendida de habitar, isto é, de uma experiência própria, da qual afastamos toda significação a que não corresponda uma doação intuitiva.

Por esta via torna-se visível, antes de tudo, e com evidência, a transitividade do habitar: habitar é apropriar-se de um lugar do espaço do mundo, ocupando-o em movimento (não há existência sem movimento). A ocupação de um espaço de modo que haja um tomar posse se assentando e um pro-jetar das preocupações próprias ali, faz dele justamente um lugar, isto é, espaço existencialmente determinado, com seus altos e baixos, seus lados, limites, proximidades e distâncias, luz e sombra e, por fim, seu teor afetivo (temeroso, confortável etc.). Ele se torna, dentro da sua pré-visibilidade existencial, um horizonte desdobrado também no tempo. Espaço com seu passado (com a marca dos meus passos, arranjos etc.) e futuro, onde eu espero que algo venha a acontecer e onde algo acontece efetivamente agora. Se o homem é "ser-nomundo", jamais está "sem lugar". Existência, corporalidade e mundo formam uma só e indiscernível estrutura com a tríade "eks-stática" da temporalidade (passado, presente e futuro). 
Mas estas determinações do lugar habitado, a saber, o aqui, o agora e a tonalidade afetiva, só têm sentido em relação, evidentemente, à corporalidade. Por meio do seu poder de abstração, universalização e idealização, o pensamento abre-nos para todos os mundos possíveis, para todos e nenhum dos lugares. Só o corpo enraíza. Portanto, o habitar designa essencialmente a apropriação do espaço que o determina, em referência à corporalidade vivida, como sítio ou lugar. O espaço geométrico, com seus pontos rigorosamente precisos, coordenadas absolutas e distâncias mensuráveis, pura construção do pensamento, não é habitável, ainda que se faça freqüentemente uso de diversas ciências exatas na construção de casas, bairros, ruas e cidades, cujos conceitos de espaço são determinados a partir da geometria e, portanto, com frequiência inumanos. $^{5}$

No sentido definido fica claro que primeiramente habitamos o próprio mundo. O homem é ser-no-mundo (Sein-in-der-Welt). Aqui não podemos destrinçar todas as implicações deste conceito fundamental da fenomenologia; apenas nos interessa ressaltar suas relações com a moradia. Neste sentido, serno-mundo significa, para o homem, habitar o mundo de forma essencial e não contingente. De fato, a existência não poderia se efetuar como tal, dando-se a si mesma a partir da sua própria experiência de ser, senão enquanto modo de existir sendo no mundo: nesta abertura pela qual, inclusive, o homem é para si mesmo.

Mas esse "mundo" que habitamos de maneira originária não deve ser concebido como espaço a conter todas as coisas à maneira de um recipiente, ou continente, universal. O mundo é, sobretudo, horizonte de presença, de manifestação e de visibilidade, de modo que ser no mundo é estar aberto para este horizonte de onde coisas e homens nos vêm ao encontro; e não encerrado em si mesmo, preso às verdades, certezas e idéias que se reencontrariam com as coisas de que seriam representações, mediante um acordo interno misterioso do pensamento - ou consciência - com o ser, garantido por Deus.

Criticando o cogito, Husserl observa que a consciência — tida de maneira ingênua como a marca interior do eu, a "consciência interior" — é intencionalidade, ou seja, sempre a consciência (de) alguma coisa que ela mesma não é. Sartre chega mesmo a dizer que a consciência não possui nenhuma interioridade, nascendo "transportada sobre um ser que não é ela". 6 "Sou para mim mesmo sendo no mundo", escreve Merleau-Ponty, ${ }^{7}$ porque o ser para si é

5 Haja vista a desobediência com que os transeuntes costumam brindar os projetistas de caminhos de traçados geométricos, abrindo trilhos no interior de canteiros, nos parques, desrespeitando passarelas e faixas etc. SARTRE. L'Être et le Néant, p. 128.

7 Phénomenologie de la perception, p. 466. 
antes retomada da existência irrefletida que eu já sou e, como tal, relação ao mundo.

A abertura da consciência, isto é, de um primeiro plano de exterioridade, é pois o campo fenomenológico em que se desenrola o ser do ego e da vida subjetiva. Trata-se da exterioridade radical em relação a si da própria essência da consciência que jamais pode revelar "para si" o "si" que a constitui originariamente. Vem daí a identificação do ser do homem ao nada, em Sartre e Heidegger, quando o primeiro identifica o nada à própria "realidade humana (considerada) em si mesma", 8 ou quando o segundo afirma que "a própria essência do homem pertence à essência do niilismo". . $\mathrm{O}$ homem se faz, pois, a partir da sua liberdade, na abertura e exterioridade do horizonte do seu mundo. Viver é, antes de mais nada, tomar posse de um mundo de onde eu me encontro.

A este mesmo modo de ser da consciência pertence o corpo próprio, se a ele estendemos idêntica noção de intencionalidade. Neste caso, a corporalidade não mais poderia ser definida por meio da experiência confusa das sensações sinestésicas. Meu corpo está aberto ao horizonte do mundo e às coisas que me saltam ao encontro a partir dele, de modo que, se acato a experiência da corporalidade, tal como me é dada, vejo que se trata sempre de determinada atitude, ou seja, de uma relação com o mundo e com os outros. Assim, quer se trate da consciência ou do corpo, sempre os surpreendemos visando algo, segundo determinada tonalidade afetiva, no primeiro caso, ou atitude para com o mundo em geral, no segundo. A existência, por isso, sempre compreende alguma coisa.

De fato as determinações da existência são todas modalidades de relações com os outros e o mundo que dependem, por sua vez, de determinações históricas e sociais que nós não escolhemos (classe social, família, país de origem etc.). A isto Sartre chamava facticidade. Esta não deve ser pensada como obstáculo ou limite à liberdade e sim a partir da idéia de tarefa implícita na possessão que nos conduz também à questão do reconhecimento. De fato, se habitar o mundo significa primeiramente se apossar da existência própria já sempre sendo, então tal habitar é também tarefa que tanto pode ser levada a bom termo (a "adaptação" à situação de fato $)^{10}$ como pode falir. É o que acontece por exemplo, na loucura, no suicídio ou na revolta.

Precisando melhor o conceito, digamos que o habitar implica certa circunscrição ou delimitação do mundo à maneira da percepção que sempre

8 SARTRE. L'Être et le Néant, p. 230.

9 HEIDEGGER, M. Sobre o problema do ser, p. 54.

10 No sentido que o utilizamos aqui, o termo adaptação não exclui evidentemente a possibilidade de distanciamento crítico e de engajamento transformador da situação da existência em geral. 
distingue figura e fundo, por fixação da figura que aparece como se fosse um relevo em relação ao fundo. Assim, também o espaço habitado surge como espécie de ancoragem da existência no horizonte do mundo: abrigo, refúgio, moradia, esconderijo. Ancoragem que se faz necessária justamente devido à determinação do mundo como horizonte.

Mas o termo horizonte não significa simplesmente um limite para a existência. $\mathrm{O}$ horizonte designa o limite do espaço que o homem não pode alcançar jamais porque é, simultaneamente, o que, sempre retrocedendo, nos seduz para as distâncias e os futuros. Ele é o campo dos desdobramentos onde a existência se projeta através do desejo. É limite inalcançável e espaço de abertura e, nessa medida, o que permite ao homem encontrar-se no mundo tal como em sua casa, na medida em que engloba o espaço determinando-o como mundo circundante finito alcançado pela visão. ${ }^{11}$

Ora, a perspectiva é inseparável da experiência do horizonte. Ela define o enraizamento do homem em sua abertura, o "ponto" a partir do qual as coisas se ordenam em relação às preocupações e aos projetos da existência. Mas esse sentido do conceito nada tem a ver com os problemas da representação pictórica e, particularmente, com a perspectiva arquitetônica, porque uma determinada tonalidade afetiva é também perspectiva - como qualquer modalidade de visão (intelectual, prática, estética etc). Assim, a perspectiva não corresponde à limitação da visão em relação a um ponto dado, limite que seria preciso ultrapassar rumo a uma apreensão totalizadora tal como pode ser obtida pela idéia ou pelo conceito. Assim procedendo, imitaríamos o pássaro ao qual Kant se refere na "Introdução" da Crítica da razão pura que, sentindo a resistência do ar, imaginava voar mais facilmente no vácuo. Ao contrário, perceber é ver em perspectiva. A visão é finita, porque a perspectiva é a determinação ontológica do horizonte para o qual ela se encontra originariamente aberta.

Assim, o conceito de perspectiva remete a um sentido da experiência do mundo em que se entrelaçam de modo indissolúvel o espaço "físico" e da existencial, uma vez que ver é lançar o olhar sobre as coisas a partir do horizonte do mundo, de um lugar do espaço mas, sobretudo, segundo uma certa compreensão prévia que alguns preferem chamar de pré-conceito. Termo que dá margens a equívocos, uma vez que apresenta a compreensão prévia do horizonte mundano como algo antecedente à visão conceitual, destinando-se, por assim dizer, a superar a familiaridade do nosso comércio vivido com ele. Ao contrário, a pré-compreensão é o espaço originário onde se desdobra a

11 Cf. BOLLNOW. Hombre y espacio, p. 73 et seq. 
própria existência, anteriormente a toda reflexão, a toda consciência tética ou construção do pensamento e mesmo anteriormente à linguagem. Trata-se dessa compreensão no sentido de capacidade manipuladora que nos permite entendermo-nos com as coisas e o mundo. A compreensão ou o entender de algo significa menos um modo de conhecimento do que um situar-se ou acharse no mundo. Vivemos tão intensamente nesse entendimento cotidiano, nesta "pré- compreensão interpretante elementar das coisas do meio, no nível do Dasein", que ele permanece quase sempre inexpresso, como modo de ser, e atemático para si mesmo. "Não obstante todas as coisas e acontecimentos, com os quais lidamos em nosso mundo vital, são pré-interpretados a partir desta compreensão precedente, como objetos para esta ou aquela utilidade". ${ }^{12}$

Freqüentemente, encontramos na arquitetura este mesmo movimento retroativo na direção de um fundamento não conceitual do seu próprio fazer, que seria capaz de lhe fornecer o apoio para um reforma radical de si mesma, sob a forma de busca da idéia primitiva de habitação. Idéia a partir da qual surgiria a compreensão enfim genuína das formas arquiteturais.

Sem dúvida, quase todo mundo concorda com uma coisa. Se é necessária a renovação da arquitetura, se é preciso reinterpretar sua função autêntica após anos de descaso, o retorno ao estado pré-consciente da edificação, ou alternativamente, à origem da consciência, irá tornar manifesto aquelas idéias primárias de onde surge uma genuína compreensão daquelas formas arquitetônicas. ${ }^{13}$

Esta idéia de retornar às origens, que constituiu, principalmente no século XVIII, a condição prévia ao exercício de todo pensamento sistemático, irá situar a arquitetura, primeiramente, na dependência do conhecimento da casa arquetípica. As especulações sobre a essência da construção reenviam à idéia da cabana primitiva, reveladora da relação adequada entre o homem e o mundo. Esta edificação "perfeita" apresenta-se também como objeto para sempre perdido, enraizando-se, por este caminho, na via religiosa que pensa a existência humana como degradação a partir de um estado de graça originário e paradisíaco. ${ }^{14}$ Como todas as técnicas e artes humanas, a arquitetura também resultaria do estado de carência ao qual a humanidade teria sido condenada por sua arrogância prometéica ou pecado. Seria, pois, necessário resgatar a casa de Adão no paraíso: habitação exemplar.

Tal atitude supõe que o conceito de casa deve necessariamente encarnar um modelo originário, um exemplar arquetípico. Não insistiremos aqui no

12 GRONDIN. Introdução à hermenêutica, p. 161.

13 RIKWERT. La casa de Adán en el paraíso, p. 34.

14 RIKWERT. La casa de Adán en el paraíso, p. 56. 
caráter equivocado deste procedimento. Apenas queremos mostrar como a fenomenologia nos propõe retornar à questão dos fundamentos do pensamento arquitetônico seguindo a via aberta da experiência vivida do habitar. Não se trata de recuperar a forma exemplar de uma impossível moradia paradisíaca, mas de prestar atenção aos modos diversos do homem de estar presente no mundo e em sua casa.

\section{III - A casa adâmica}

Quando não se trata da casa original a fundamentação da arquitetura buscou freqüentemente equacionar as diversas dimensões da existência em um sistema de necessidades mais ou menos universais às quais o artefato arquitetônico deveria se adaptar. A casa, como queria Corbusier, é um sistema de lugares funcionais adaptados às necessidades decorrentes das atividades básicas da vida que ali se desenrolam. O arquiteto deverá, pois, buscar apoio na competência dos diversos saberes que equacionam as necessidades universais da vida humana que a moradia deverá satisfazer.

Desde Aristóteles, a questão da redução do sentido das atividades humanas à satisfação das necessidades já era radicalmente criticada. A pólis, morada onde convivem os "homens de bem", escreve o estagirita, não é uma simples reunião de pessoas tendo em vista o comércio ou a proteção mútua. Os homens reúnem-se para viver a melhor vida possível, isto é, a vida feliz e virtuosa. Por isso, não se deve traduzir zoon politikon por "animal social", uma vez que também os animais se associam e têm formas de vida social. Ao contrário, só o homem é animal político. ${ }^{15} \mathrm{O}$ estatuto econômico/jurídico da sociedade é, pois, superado pela dimensão ético/política que constitui a existência propriamente humana. Em outras palavras, o possível é mais vasto do que a necessidade e por isso o homem é livre, no sentido em que Marx dizia que o reino da liberdade começa onde termina o reino da necessidade. A cidade é o lugar onde os possíveis mais humanos podem se realizar e, por isso, o homem a habita.

Sem dúvida alguma, no momento em que tudo parece administrável, em que a planificação se impõe como imperativo inultrapassável da racionalidade política, em que a pré-visibilidade aparece como o baluarte último da cientificidade, as necessidades surgem no âmbito da existência humana como salvação para a ambição do cálculo, pois elas e suas satisfações sempre perfazem

15 Sobre a tradução da expressão zoon politikon por "animal social" e de zoon logon ekhon por "animal racional”, veja-se ARENDT. A condição humana, p. 30-36. 
equações unívocas. Se a existência se resolvesse em demandas objetivas de coisas materiais, a política poderia ser, enfim, reduzida às atividades básicas destinadas a manter o barco em seu curso - para usar a metáfora da embarcação tantas vezes retomada por Platão e Aristóteles. ${ }^{16}$ Mas como determinar racionalmente o próprio curso da embarcação?

Na Fenomenologia do espírito, Hegel mostra que o desejo propriamente humano antecipa imaginariamente sua própria satisfação, de modo a criar esse hiato fantástico a medrar sempre entre a realidade positiva e o possível, sobre o que se ergue a liberdade. Concepção, que, mutatis mutandis, será a mesma de Freud quando, em A Interpretação de sonhos, define o desejo. ${ }^{17}$ Portanto as necessidades não podem constituir, como a casa de Adão, um fundamento legítimo ao qual a arquitetura possa recorrer a fim de constituir-se como verdadeira ciência da arké humana. Como afirma Lefebvre,

se bem que seja verdadeira a existência de necessidades funcionalizáveis, existe também o desejo, ou os desejos, à margem e mais além das necessidades inscritas nas coisas e na linguagem. Ademais, as necessidades estão conservadas, recebidas, classificadas em função de imperativos econômicos, de normas e valores sociais. Portanto, a classificação e denominação das necessidades tem um caráter contingente, paradoxalmente, são instituições. Por cima das necessidades se alçam as instituições que as governam ou as classificam ao estruturá-las. ${ }^{18}$

É aí, portanto, onde as ciências se vêem obrigadas a se calar, perante o confuso, o desconcerto, a obscuridade, que a filosofia deve intervir. Por que não contrapor ao funcionalismo da teoria das necessidades, na constituição da arquitetônica da arquitetura, uma ontologia do desejo? Ontologia que necessitaria, por sua vez, de uma nova teoria fenomenológica da corporalidade, pois a casa não poderia ser concebida como lugar de realização de funções senão quando o corpo já tiver sido reduzido à condição de organismo, ou seja, de um feixe de funções mais ou menos biológica e fisiologicamente definíveis.

Desde o início, seria preciso afastar a tendência a interpretar o modo de ser do corpo à maneira das coisas. Como afirmava Merleau-Ponty, o contorno do corpo próprio é uma fronteira que as relações comuns do espaço não ultrapassam. "Meu corpo não é um agregado de órgãos justapostos no espaço", como o mouse do computador e o telefone. "Eu tenho dele uma posse indivisível". 19

16 Cf. PlatÃO. A República, IX, 4-5, 576-577; e ARISTÓTELES. Política, III, 5, 1280.

17 FREUD. Obras completas, v. II, p. 602-03.

18 LEFEBVRE. La revolución urbana, p. 76.

19 MERLEAU-PONTY. Phénomenologie de la perception, p. 151. 
A espacialidade do corpo corresponde muito mais à idéia de uma esquematização do ambiente circundante a partir da atitude própria do sujeito em relação ao mundo, os outros e as coisas, esquematização por meio da qual não se tem apenas a posse de um mundo, mas também, e essencialmente, do próprio corpo, do que à idéia de coordenadas geométricas.

Assim como a idéia da casa funcional não pode ser separada do marco da sociedade industrial moderna da qual nasce, também a redução do conceito arquitetônico de espaço à geometria euclidiana está condicionada à rarefação do espaço por sua crescente urbanização. É por isso que economistas, planejadores e políticos se referem à casa como simples espaço construído, definido quantitativamente pela área ocupada. Assim procedendo, concebem a moradia tal como o senso comum e a ciência concebem o corpo: não como centro de espacialização e sim como coisa no espaço físico. Ora, como já vimos, a casa não é um simples espaço construído, mas espaço habitado, cujos elementos qualificativos não dependem necessariamente das definições dimensionais das relações espaciais.

Somos, assim, remetidos pela problemática ao tipo de investigação que Bachelard chamou de "topo-análise", em oposição à investigação de cunho topográfico, tal como seria praticada a partir das noções geométricas de espaço. Na sua Poética do espaço, Bachelard afirma que a análise fenomenológica do seu objeto, quando se trata de pensar a casa, não remete a uma arqueologia da cabana primitiva e arquetípica, nem a um sistema de necessidades definidas, mas às imagens do espaço feliz. Este modo de investigar nos situa diante do valor do espaço, do espaço desejado, quer sejam este valor e este desejo correlacionados a uma variável objetiva, quer sejam simplesmente imaginados. Examinada assim, a imagem da casa tornar-se-ia "a topografia do nosso ser íntimo". 20

É dessa forma que os problemas empíricos relativos à descrição dos diversos tipos de moradia - a que já aludimos no início deste trabalho seriam superados na direção de uma fenomenologia do ato de habitar, ligado a todas as dialéticas da vida e, principalmente, "ao modo como nos enraizamos em algum canto do mundo". ${ }^{21}$ Trata-se, portanto, da casa arquetípica, oriunda da análise poética dos lugares íntimos, dos espaços ainda não colonizados pela lógica ou pela rigidez das rotinas ligadas ao trabalho diário, ao manuseio de coisas e ao consumo de mercadorias, ou mesmo à convivência formal com os outros. Mas em Bachelard a casa surge como espaço excedente em relação 
ao âmbito das sujeições heterogêneas que colonizam a existência, definindose a arquitetura, a partir daí, como verdadeira atividade ética, na medida em que a casa vai funcionar como abrigo, porém, não mais contra a maldade dos homens, as intempéries naturais ou a ferocidade animal. Ao invés disso, $a$ casa ofereceria proteção em relação ao espaço colonizado da vida cotidiana, espaço das atividades destinadas a satisfazer um objetivo distinto delas próprias - como ocorre no trabalho, por exemplo - ao contrário das atividades artísticas, eróticas e intelectuais que constituem "em si", e um dia constituirão "para si", a consciência e o modo de vida autêntico de todo homem.

De fato a concepção da casa como lugar feliz e, simultaneamente, como abrigo de práticas antagônicas em relação à cotidianidade colonizada pelas atividades de consumo e produção, determinada pelas necessidades de expansão e reprodução do capital, impõe um esclarecimento relativo ao que entendemos por felicidade e "atividades autônomas".

Que nos seja permitido retomar uma última vez a ética de Aristóteles, segundo a qual a felicidade reside na forma vivida da atividade, mais exatamente, no prazer ligado à perfeição do ato e sua fruição: eupraxia. ${ }^{22}$ Mas as ações técnicas ou poéticas não podem se pautar exclusivamente pelo telos do prazer da vida, uma vez que a forma de efetuá-las depende de prescrições objetivas de toda espécie. Para dar apenas um exemplo, derivado da tekné, as ações deste tipo têm como critério de racionalidade determinante a eficácia no trato com a coisa a ser produzida, que define o êxito da ação. Evidentemente, a força viva do trabalho do artesão (dou este exemplo porque certamente não se espera que a atividade do trabalhador fabril, condenado a apertar um simples parafuso oito horas por dia, possa ser dita prazerosa, a não ser por uma espécie de perversão) encontra-se carregada de habilidades, de modo que não é impossível pensar o seu esforço produtivo como algo capaz de dar lugar à expansão das potencialidades subjetivas imanentes da sua vida. Porém, o trabalho deve se efetuar de acordo com as condições objetivas oferecidas ao produtor pela sociedade em que vive. Convém lembrar que ninguém produz isoladamente. ${ }^{23}$ Além disso, o trabalho é atividade essencialmente heterônoma,

22 Remeto o leitor interessado em uma explanação mais extensa sobre o tema ao meu artigo publicado na revista DISSERTATIO, de Pelotas (RS), n. 07, p. 67-89. A propósito, Aristóteles define a casa como "abrigo contra as destruições dos ventos, do calor e das chuvas" (Ética a Nicômaco, b 3-5). Certamente hoje as definições da casa apontariam mais para o lado da atividade (de consumo, de repouso, alimentação etc) do que para o confronto com as forças adversas da natureza.

23 O conceito de trabalho que utilizamos aqui não designa as formas remuneradas de atividade existentes na sociedade, e sim a atividade efetivamente produtiva de uma coisa útil, a transformação material da natureza. Assim, um caixa de banco, ou um estivador do cais do porto não trabalham. Ao contrário, um pescador amador, que não vende seu peixe, que se diverte e goza com sua atividade, trabalha, pois transforma a natureza - o peixe no rio - em algo útil — o peixe pescado. 
no sentido de que visa, acima de tudo, satisfazer as necessidades materiais da vida, satisfação, que no nosso caso histórico fica na dependência de todas as determinações econômicas da produção submetida ao valor de troca. Desse modo, a satisfação plena da vida não poderia advir senão daquelas atividades que possibilitassem a expansão ilimitada das potencialidades subjetivas dos indivíduos, tais como a arte, a ciência, o amor — sob todas as suas formas e os jogos.

Neste sentido, escreve o filósofo de $O$ Capital, "a condição fundamental do desenvolvimento humano é a redução da jornada de trabalho", ${ }^{24}$ o que só é possível mediante o aumento da produtividade do trabalho. Esse aumento pode se efetuar por meio da aceleração do ritmo do trabalho, ou aperfeiçoando tecnológica e cientificamente o processo de produção. No primeiro caso, tratase de uma forma irracional de agir, pois tem como limite o esgotamento das forças físicas e intelectuais dos trabalhadores, de modo que o tempo livre se resumirá em tempo de descanso, de preparação para nova jornada de trabalho, a vida se reduzindo à sobrevivência.

Assim, só o aumento, proporcionado pela ciência, da produtividade do trabalho, da quantidade de valores de uso produzidos em determinado tempo, permitirá reduzir como um todo a jornada de trabalho sem comprometer a tarefa histórica principal do homem: construir, e habitá-lo, o reino da liberdade. Adverte Marx,

Mas este esforço situar-se-á sempre no reino da necessidade. Além dele começa o desenvolvimento das forças humanas como um fim em si mesmo, o reino genuíno da liberdade, o qual só pode florescer tendo por base o reino da necessidade. E a condição fundamental desse desenvolvimento é a redução da jornada de trabalho. ${ }^{25}$

Assim, o desenvolvimento das forças humanas como fim em si mesmo, a que se destina a casa poeticamente imaginária de Bachelard, depende do desenvolvimento científico que propicia as condições para a redução da jornada de trabalho, conduzindo, no limite, à desubjetivação do processo produtivo. De fato, estas questões nos remeteriam de novo a uma espécie de análise político/fenomenológica da casa que não poderemos, evidentemente, fazer aqui, deixando-a apenas sugeridas. Pois o homem habita sua casa no tempo livre. Participar, pois, no movimento de conquista do tempo é a primeira tarefa da arquitetura que deseje edificar no espaço da liberdade humana, a casa arquetípica dos homens felizes. 


\section{Referências}

ARENDT, H. A condição humana. Rio de Janeiro: Forense, 1983.

BACHELARD, G. La poétique de l'espace. Paris: PUF, 1957.

BOLLNOW, F. Hombre y espacio. Barcelona: Labor, 1969.

CHALENDAR, J. L'Aménagement du temp. Paris: Desclée de Brower, 1971.

FRANÇOISE, C. O Urbanismo. São Paulo: Perspectiva, 1979.

FREUD, S. Obras completas. Edição Standard Brasileira. XXII v. Rio de Janeiro: Imago, 1969. p. 602-03. v. II.

GRONDIN, J. Introdução à hermenêutica. São Leopoldo: UNISINOS, 1999.

HEIDEGGER, M. El ser y el tiempo. México: Fondo de Cultura, 1984.

1969. . Sobre o problema do ser. Trad. Ernildo Stein. São Paulo: Duas Cidades,

HUSSERL, E. Logique formale et logique transcendentale. Trad. Suzanne Bachelard.

Paris: PUF, 1965.

LEFEBVRE, H. La revolución urbana. Madrid: Gredos, 1978.

MARX, K. O Capital. Trad. Reginaldo Sant'Anna. São Paulo: Difel, 1985. 6 v.

MERLEAU-PONTY, M. Phénomenologie de la perception. Paris: Gallimard, 1945.

RIKWERT, J. La casa de Adán en el paraíso. Barcelona: Gustavo Gili, 1974.

SARTRE, J-P. L'Être et le Néant. Paris: Gallimard, 1956. 